\title{
Article \\ Environmental and Fecal Indicator Organisms on Fruit Contact Surfaces and Fruit from Blueberry Mechanical Harvesters
}

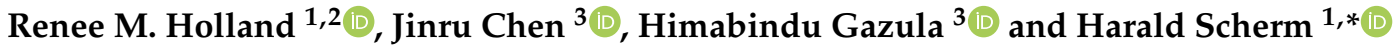 \\ 1 Department of Plant Pathology, University of Georgia, Athens, GA 30602, USA; reneemh@uga.edu \\ 2 University of Georgia Extension, Alma, GA 31510, USA \\ 3 Department of Food Science and Technology, University of Georgia, Griffin, GA 30223, USA; \\ jchen@uga.edu (J.C.); bindu.gazula@gmail.com (H.G.) \\ * Correspondence: scherm@uga.edu
}

check for updates

Citation: Holland, R.M.; Chen, J.;

Gazula, H.; Scherm, H.

Environmental and Fecal Indicator Organisms on Fruit Contact Surfaces and Fruit from Blueberry Mechanical Harvesters. Horticulturae 2022, 8, 20. https://doi.org/10.3390/

horticulturae 8010020

Academic Editor:

Douglas D. Archbold

Received: 23 November 2021

Accepted: 20 December 2021

Published: 24 December 2021

Publisher's Note: MDPI stays neutral with regard to jurisdictional claims in published maps and institutional affiliations.

Copyright: (c) 2021 by the authors. Licensee MDPI, Basel, Switzerland. This article is an open access article distributed under the terms and conditions of the Creative Commons Attribution (CC BY) license (https:/ / creativecommons.org/licenses/by/ $4.0 /)$.

\begin{abstract}
Although previous studies have examined microbial loads on food contact surfaces in blueberry packing plants, there is currently no information regarding microbial risks associated with mechanical berry harvesters used in commercial blueberry production. In this study, we surveyed up to nine fruit contact surfaces on seven mechanical harvesters in each of 2015 and 2016 in the field. These surfaces included the shaking rods at the front of the harvester, the sidewalls of the harvesting tunnel behind the shaking mechanism, the catcher plates collecting the detached berries, horizontal and vertical fruit conveyor belts, and berry lugs collecting the fruit at the back of the harvester. Swab samples were collected from each surface three times a day (morning, noon, and evening) and assessed for environmental and fecal indicator organisms including total aerobes, total yeasts and molds, coliforms and fecal coliforms, and enterococci. At the same time points, fruit samples were assessed for microbial loads before the fruit entered each harvester and after they exited the harvester. Results showed statistically significant differences in microbial loads among harvester surfaces, whereas the effect of sampling time was generally not significant. High levels of total aerobes and total yeasts and molds were recorded, especially on horizontal surfaces and/or those located at the bottom of the harvester such as the lower sidewall, the catcher plates, and the horizontal conveyor belt. These surfaces therefore should be targeted by cleaning and sanitization practices. There was also statistical evidence that passage through the harvester may increase the levels of the environmental microorganisms on fruit in the field. In contrast, fecal indicator organisms such as fecal coliforms and enterococci were detected only sporadically and at very low densities on harvester surfaces and blueberry fruit, and there was no evidence that passage through the harvester increased their levels on the fruit. Berry lugs consistently harbored microbial loads, and given their movement back and forth between the field and the packing plant, deserve particular attention with regard to cleaning, sanitization, and storage protocols.
\end{abstract}

Keywords: blueberry; environmental indicator organisms; fecal indicator organisms; mechanical harvest; microbial quality

\section{Introduction}

Comprehensive, science-based standards have been legislatively mandated by the Food and Drug Administration in the United States for the safe growing, harvesting, packing, and holding of fruits and vegetables for human consumption as part of the Produce Safety Rule under the Food Safety Modernization Act [1]. This legislation intended to clarify that people and businesses that provide food to the public, whether they produce, process, transport, or sell food, are responsible for taking necessary steps to ensure hazards that make food unsafe have been identified and controlled [2]. It requires preventative measures to clean, sanitize, and maintain equipment to prevent contamination of produce and food contact surfaces with microbial pathogens of food safety concern. The blueberry industry has made great progress in implementing appropriate cleaning and sanitation 
procedures in fruit packing plants [3], but guidance on how to best clean and sanitize field equipment with food contact surfaces, such as mechanical berry harvesters, is currently lacking. Cleaning and sanitization of farm equipment have been recommended for many years [4-6] but practical application is lagging. Growers consider sanitization protocols time-consuming and labor-intensive; hence, they need science-based information to help decide which harvester surfaces to prioritize for cleaning and sanitization to optimize the allocation of labor resources while minimizing microbial risks.

Testing for environmental and fecal indicator organisms, such as total aerobes, total yeast and molds, enterococci, coliforms, and fecal coliforms, is standard practice in environmental monitoring and food safety [7-9]. Very limited information is available on microbial loads of these organism groups on mechanical produce harvesters. In a preliminary microbial risk assessment in blackberry (Rubus spp.), a mechanical harvester was tested for total aerobic plate counts by sampling eight locations on the harvester before and after harvesting [10]. Microbial populations varied substantially for different sample locations and there was no significant difference in values of overall aerobic plate counts on clean vs. dirty (after harvest) surfaces [10]. Thus, it was concluded that the mechanical harvester was likely not a source of contamination. This pilot study was conducted as a one-time assessment on a single harvester, only one microbial indicator group (total aerobes) was evaluated, and the effect of passage through the harvester on microbial populations on fruit was not examined.

In another preliminary study on blueberry, Mehra et al. [11] determined counts of total aerobes, total yeasts, total molds, coliforms, and E. coli from fruit samples that had been either hand-harvested or machine-harvested. The authors noted statistical differences among years and cultivars but not between harvest methods. However, microbial loads on mechanical blueberry harvesters used commercially have not been quantified previously, nor have different harvester surfaces been examined relative to their cleanability and ease of sanitization. Thus, the purpose of this study was to quantify the microbial loads of environmental and fecal indicator organisms on various harvester surfaces to enable a direct comparison of the relative microbial risk associated with these surfaces. This will serve as a first step toward aiding growers in developing cleaning protocols that help improve the hygienic conditions of blueberry harvesters and the microbial quality of fruit, thereby reducing the possibility of blueberry-associated foodborne illness.

\section{Materials and Methods}

\subsection{Mechanical Harvester Survey}

A typical over-the-row harvester in commercial blueberry production is comprised of a picking tunnel with aluminum or stainless-steel sidewalls (Figure 1A,B) that houses two cylindrical towers of shaking rods (Figure 1C,D) at the front of the tunnel. Spring-loaded catcher plates (Figure 1E) at the bottom of the tunnel hug the base of the plant as the harvester passes over it. Berries detached by the shaking rods fall on the catcher plates from where they deposit on a horizontal conveyor belt (Figure 1F), one on the bottom on each side of the harvester tunnel. For a conventional bottom-loader harvester, the berries on the conveyor belt then pass by a leaf blower and drop into plastic berry lugs (Figure 1G); these lugs are removed manually when filled and transported to the packinghouse. For a top-loader harvester, the berries are deposited onto an additional conveyor belt (Figure $1 \mathrm{H}$ ) that lifts them vertically to the top level of the harvester; there, the berries pass through a leaf blower and a rubberized canvas flap (Figure 1I) before dropping into the lug. The materials that typically make up these harvester surfaces are listed in Table 1.

In June of 2015, seven mechanical blueberry harvesters (four bottom-loaders and three top-loaders) from seven different growers were surveyed as they were harvesting fruit in commercial rabbiteye blueberry (Vaccinium virgatum) fields near Alma, GA, USA. Another seven mechanical harvesters were surveyed in 2016 (four bottom-loaders and three top-loaders), whereby five of the harvesters overlapped between the two years. Each harvester was sampled for microbial populations three times on the same day: once before 
harvesting commenced in the morning (AM), at mid-day (typically during lunch break), and in the evening before or after harvesting stopped for the day (PM). Thus, the three sampling times per day provided the opportunity to assess the potential for accumulation of microbes over time, whereas the seven harvesters per season provided independent replicates to ensure the results are broadly representative of current industry practices. Specific sampling dates were 4, 5, 12, 18, 19, 25, and 26 June in 2015 and 8, 10, 13, 20, 21, 27, and 28 June in 2016. Weather conditions on these sampling dates were typical for southern Georgia, with average daily minimum and maximum temperatures ranging from 17.8 to $24.9^{\circ} \mathrm{C}$ and 29.9 to $36.4^{\circ} \mathrm{C}$, respectively. Trace amounts of precipitation were recorded on two of the days.

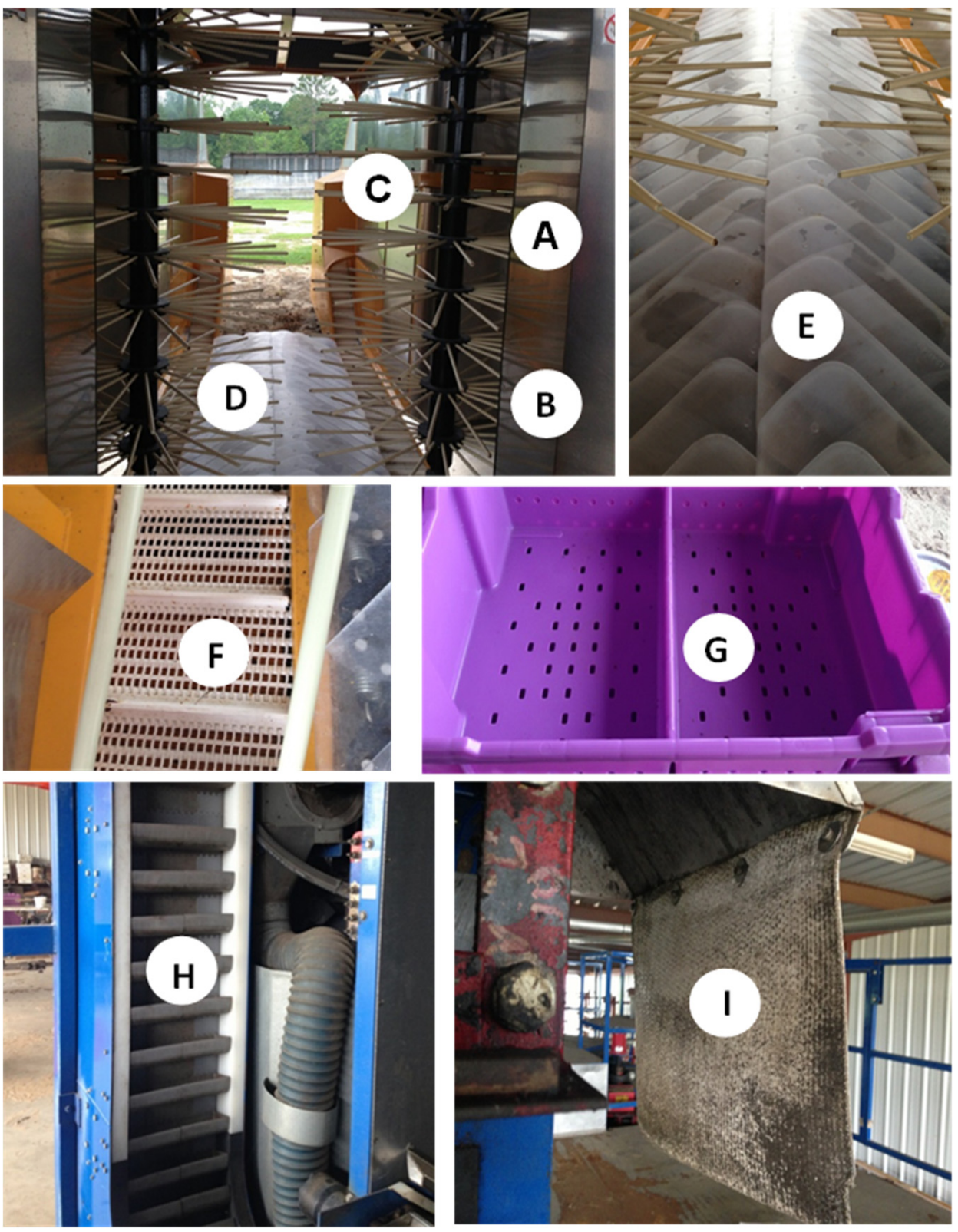

Figure 1. Photographs of blueberry mechanical harvester surfaces for microbial sampling: upper tunnel sidewall (A), lower sidewall (B), upper shaking rods (C), lower shaking rods (D), catcher plates (E), horizontal conveyor belt (F), berry lug (G), vertical conveyor belt (H), and filling flap (I). The latter two surfaces are found only on top-loader harvesters. 
Table 1. Composition of blueberry mechanical harvester fruit contact surfaces assessed in this study.

\begin{tabular}{cc}
\hline Surface & Material \\
\hline Shaking rod & Polyethylene \\
Tunnel sidewall & Aluminum or stainless steel \\
Catcher plates & Extruded polycarbonate \\
Conveyor belt & Acetal plastic or stainless steel \\
Filling flap & Rubberized canvas \\
Berry lug & High-density polyethylene \\
\hline
\end{tabular}

Microbial swab samples were collected from the aforementioned harvester surfaces, seven surfaces for bottom-loaders and nine surfaces for top-loaders (Figure 1). This resulted in 21 and 27 samples for each bottom- and top-loader harvester, respectively, for a total of 165 samples per year. No information was available on the cleaning and sanitization history of each harvester prior to sampling, but blueberry harvesters in commercial production generally were not cleaned daily at the time of this study.

\subsection{Swabbing from Harvester Surfaces}

With the aid of a $10-\mathrm{cm} \times 10$-cm template, surfaces were swabbed with sterile WhirlPak Speci-Sponge environmental surface sampling sponges (Nasco) that had been soaked in $25 \mathrm{~mL}$ of refrigerated Dey-Engley (DE) neutralizing broth (Becton Dickinson) in a sterile sampling bag. For surfaces that were not flat or had perforations (e.g., Figure 1C,D,F), no template was used but a $100-\mathrm{cm}^{2}$ area was delineated and swabbed instead. Using surface-disinfested nitrile gloves, the sponge was removed from the bag, excess buffer was squeezed out, and the sponge used to swab the area with even pressure $(\sim 25 \mathrm{~N})$, ten strokes vertically and ten strokes horizontally. The sponge was placed back in the sampling bag which was then sealed. Samples were placed in an iceless thermoelectric cooler and transported back to the lab for processing.

\subsection{Fruit Sample Collection}

Fruit samples were taken in the field at the same time points as the surface swabs for all harvesters. Using surface-disinfested gloves, one sample (referred to as pre-harvester sample henceforth) was taken from a blueberry bush just before the plant entered the tunnel of the harvester. A second sample (post-harvester sample) was collected from the berry lug immediately after the fruit had traveled through the harvester. Each sample consisted of $50 \mathrm{~g}$ of fruit, and fruit samples were stored in sterile Nasco Whirl-Pak sampling bags in a thermoelectric cooler in an air-conditioned vehicle for transit to the lab for processing. This process resulted in 42 fruit samples per year.

\subsection{Microbial Enumeration}

Surface and fruit samples were analyzed for total aerobic plate counts, total yeasts and molds, coliforms and fecal coliforms, and enterococci [7]. After hand massaging the WhirlPak bag with sponge for $1 \mathrm{~min}$ to release the microbial cells into the DE broth, a 100- $\mu \mathrm{L}$ sample was dilution-plated from the sample bag onto Petri plates with the appropriate media: tryptic soy agar (TSA; BD Difco) for total aerobic plate counts, acidified potato dextrose agar (aPDA; BD Difco) for yeasts and molds, MacConkey agar for coliforms and fecal coliforms, and Enterococcus agar for enterococci. All plating was done in duplicate. For pre- and post-harvester fruit samples, each $50-\mathrm{g}$ sample was transferred into a new sterile Whirl-Pak bag containing $100 \mathrm{~mL}$ of $1 \times$ PBS buffer and rinsed for $30 \mathrm{~min}$ by setting on a shaker set at $100 \mathrm{rpm}$ [12]. One-hundred microliter samples were taken directly from the rinsate bag and dilution-plated as described previously.

Petri plates were incubated as follows: total aerobes for $24 \mathrm{~h}$ at $37^{\circ} \mathrm{C}$, yeasts and molds for $72 \mathrm{~h}$ at $21.1-23.8^{\circ} \mathrm{C}$, coliforms and enterococci for $24 \mathrm{~h}$ at $37^{\circ} \mathrm{C}$, and fecal coliforms for $24 \mathrm{~h}$ at $44.5^{\circ} \mathrm{C}$. The number of colony-forming units (CFU) was counted for each plate and converted to $\mathrm{CFU} / \mathrm{cm}^{2}$ for the harvester surfaces and $\mathrm{CFU} / \mathrm{g}$ of fruit for the fruit samples. 
Theoretical detection limits were $1.25 \mathrm{CFU} / \mathrm{cm}^{2}$ of surface and $10 \mathrm{CFU} / \mathrm{g}$ of fruit. Means were calculated for each harvester, surface, and sampling time.

Further confirmation testing of fecal indicator organisms was conducted by streaking suspect enterococci colonies onto Enterococcus agar, incubating for $24 \mathrm{~h}$ at $37^{\circ} \mathrm{C}$, and inoculating emerging colonies into brain-heart infusion (BHI) broth with $6.5 \% \mathrm{NaCl}$ using a sterile microbial loop. Inoculated BHI tubes were incubated for $24 \mathrm{~h}$ at $37^{\circ} \mathrm{C}$, and a turbid tube was considered positive for enterococci. For fecal coliforms, suspect colonies were streaked fresh onto MacConkey agar and incubated for $24 \mathrm{~h}$ at $44.5^{\circ} \mathrm{C}$. Emerging colonies were inoculated into E. coli broth with a Durham tube inside, incubated for $24 \mathrm{~h}$ at $37^{\circ} \mathrm{C}$, and turbid tubes with gas production were considered positive for fecal coliforms. The fecal coliform suspect colonies were further tested by stabbing and streaking onto triple sugar iron slants. Where positive, the bacteria fermented at least one of the sugars present (lactose, sucrose, or glucose), producing acid that changes the red $\mathrm{pH}$-sensitive dye to yellow, and also producing hydrogen gas which can be seen as bubbles between agar and glass and/or the space at the bottom of the tube where the agar has lifted from the bottom of the tube due to gas production.

For data analysis, mean CFU densities were $\log _{10}(x+1)$-transformed and subjected to mixed-model analysis of variance for a split-plot design where time (AM, noon, PM) was the main-plot, harvester surface (or pre- and post-harvester fruit location) was the sub-plot, and the harvesters served as replicates (blocks); the analysis was done separately by year and also for the combined data set (both years). Where appropriate in the absence of statistical interactions, main effect means were compared using Tukey's test at $p=0.05$. The analysis was conducted using PROC GLIMMIX in SAS v9.4 (SAS Institute, Cary, NC, USA).

\subsection{Identification of Mechanical Harvester Microorganisms}

Representative microbial cultures from the 2015 and 2016 harvester surface dilution platings were retained for presumptive identification of common microbial genera and species for future work on surface sanitization [13]. Additional cultures for characterization were obtained in June of 2017 by swabbing seven mechanical harvesters (four bottomloaders and three top-loaders), dilution-plating the DE broth solutions onto TSA and aPDA, and incubating plates as described above. Colonies of different bacterial phenotypes from TSA plates and of yeasts and molds from aPDA plates were selected and subjected to repeated single-colony isolation until pure cultures were obtained. Representative isolates were sequenced at the 16S rRNA (primers 27F and 1492R [14]) and ITS (primers ITS1F and ITS4 [15]) regions for bacteria and yeasts/molds, respectively, at the Plant Molecular Diagnostics Lab at the University of Georgia Tifton Campus. Preliminary identifications were based on BLAST comparisons with nucleotide sequences available in NCBI Genbank using default parameters, selecting the short queries option, and setting word size to 28 .

\section{Results}

\subsection{Microbial Loads on Harvester Surfaces}

The two environmental organism groups, total aerobes (Figure 2A) and yeasts and molds (Figure 2B), were consistently detected on all harvester surfaces at relatively high population densities of $10^{4}$ to $10^{9}$ and $10^{4}$ to $10^{5} \mathrm{CFU} / \mathrm{cm}^{2}$, respectively. Coliforms also occurred on all surfaces, but population densities were several orders of magnitude lower and more variable, averaging between $10^{1}$ and $10^{3} \mathrm{CFU} / \mathrm{cm}^{2}$ (Figure 2C). Colony counts of fecal coliforms (Figure 2D) and enterococci (Figure 2E) were the lowest $\left(0\right.$ to $10^{2} \mathrm{CFU} / \mathrm{cm}^{2}$ on average), and most of the swab samples from the front end of the harvester (upper and lower shaking rods, upper sidewall) had no detectable colonies. Analysis of variance indicated that microbial loads were affected by harvester surface in most comparisons ( 8 out of 10 across the 2 years, 5 out of 5 in the combined data), whereas the effect of sampling time (AM, noon, or PM) was significant only in 4 out of 10 comparisons across the 2 years and 1 out of 5 for the combined data (Table 2). 
For total aerobes, populations were consistently higher on the lower sidewall of the tunnel, the catcher plates, and the conveyor belt compared with the upper shaking rods, the lower rods, and the upper wall (Figure 2A). Numbers were intermediate and more variable on the berry lug.
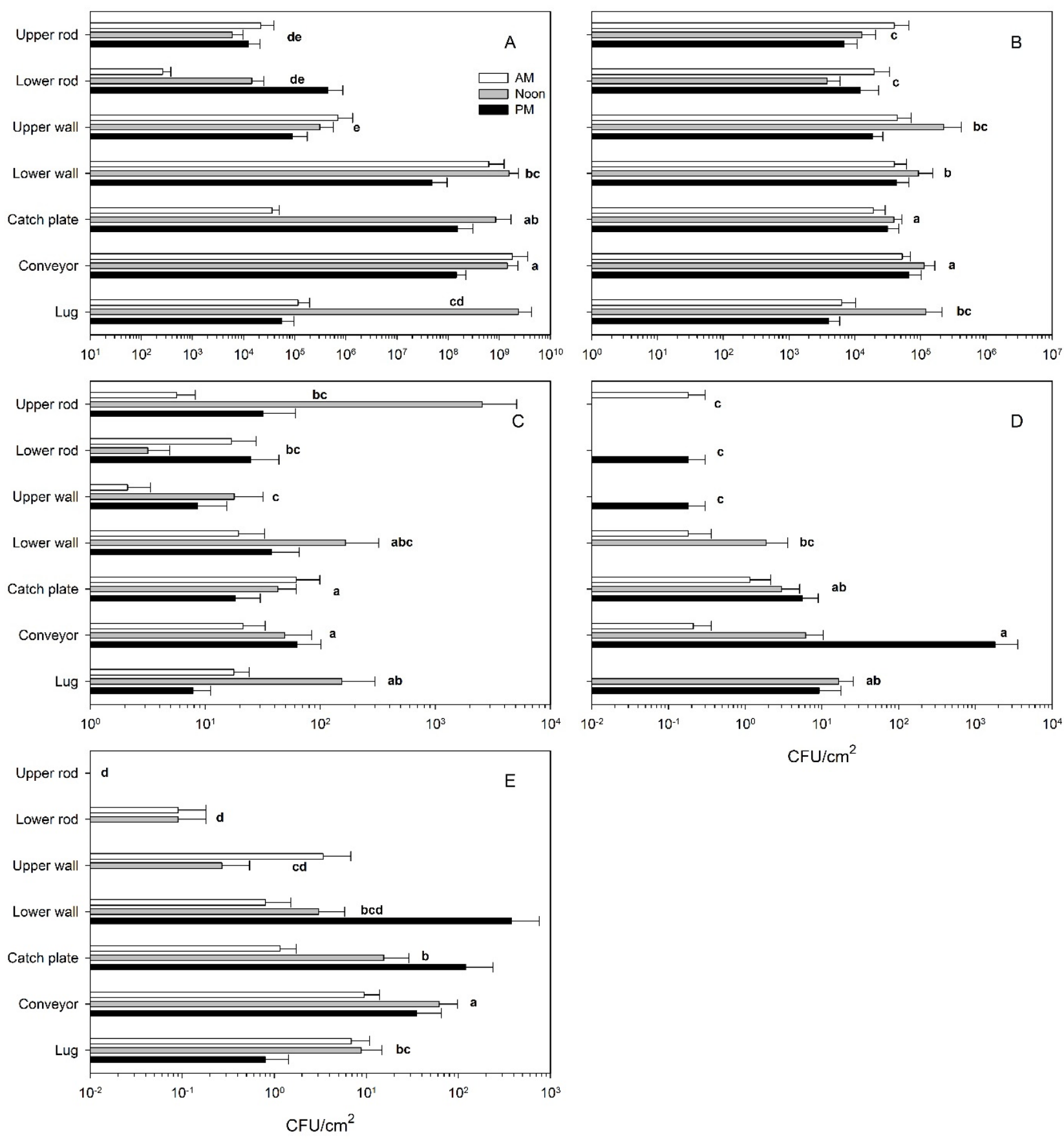

$\mathrm{CFU} / \mathrm{cm}^{2}$

Figure 2. Microbial loads on different surfaces of blueberry mechanical harvesters in the field when sampled in the morning (AM), at noon, and in the evening (PM). (A) Total aerobes, (B) total yeasts and molds, (C) coliforms, (D) fecal coliforms, and (E) enterococci. Values are means and standard errors across seven harvesters sampled in each of 2 years. Bars with the same lower-case letters are not significantly different for comparison of the surface main effect (Tukey's test, $p=0.05$ ). Analysis based on $\log _{10}(x+1)$-transformed values, untransformed values are shown in the figures. CFU $=$ colony-forming units. 
Table 2. $p$-values of mixed-model analysis of variance for the effects of harvester surface (upper shaking rods, lower shaking rods, upper sidewall, lower sidewall, catcher plates, conveyor belt, and berry lug) and time (AM, noon, $\mathrm{PM})$ on the population density $\left(\log _{10}(x+1)\right.$ colony-forming units per $\mathrm{cm}^{2}$ ) of environmental and fecal indicator organisms across seven mechanical blueberry harvesters in each of 2015 and $2016^{1}$.

\begin{tabular}{|c|c|c|c|c|c|}
\hline \multirow[b]{2}{*}{ Factor } & \multicolumn{5}{|c|}{ Organism Group } \\
\hline & $\begin{array}{c}\text { Total } \\
\text { Aerobes }\end{array}$ & $\begin{array}{l}\text { Yeasts and } \\
\text { Molds }\end{array}$ & Coliforms & $\begin{array}{c}\text { Fecal } \\
\text { Coliforms }\end{array}$ & Enterococci \\
\hline 2015 & & & & & \\
\hline Surface (S) & $\leq 0.0001$ & $\underline{0.0005}$ & 0.1989 & 0.4749 & $\underline{0.0023}$ \\
\hline Time (t) & 0.3498 & $\underline{0.0012}$ & 0.1308 & $\underline{0.0348}$ & 0.5514 \\
\hline $\begin{array}{l}S \times t \\
2016\end{array}$ & 0.8214 & $\underline{0.0085}$ & 0.7533 & 0.6646 & 0.4467 \\
\hline Surface (S) & $\leq 0.0001$ & $\leq 0.0001$ & $\underline{0.0006}$ & $\underline{0.0030}$ & $\leq 0.0001$ \\
\hline Time (t) & $\underline{0.0214}$ & 0.6740 & 0.2312 & $\underline{0.0093}$ & 0.2308 \\
\hline $\mathrm{S} \times \mathrm{t}$ & 0.7211 & 0.1297 & 0.6336 & 0.0775 & 0.5571 \\
\hline $\begin{array}{c}\text { Combined } \\
\text { years }\end{array}$ & & & & & \\
\hline Surface (S) & $\leq 0.0001$ & $\leq 0.0001$ & $\underline{0.0046}$ & $\underline{0.0005}$ & $\leq 0.0001$ \\
\hline Time (t) & 0.3853 & 0.1128 & 0.7409 & $\underline{0.0080}$ & 0.3289 \\
\hline $\mathrm{S} \times \mathrm{t}$ & 0.7432 & 0.3083 & 0.9977 & $\overline{0.0110}$ & 0.4800 \\
\hline
\end{tabular}

${ }^{1}$ Significant $p$-values are underlined.

Although statistical differences were observed among harvester surfaces for total yeasts and molds (Figure 2B), these differences were relatively small in magnitude. Again, counts were the most variable on the lug.

Coliform counts were variable on most surfaces, with the highest averages observed for the catcher plates and conveyor belt (Figure 2C); average counts were lowest on the upper sidewall. Fecal coliforms were mostly absent from the upper and lower rods and the upper sidewall, but were detected more consistently (albeit at low densities typically $<10^{1} \mathrm{CFU} / \mathrm{cm}^{2}$ ) on the catcher plates, conveyor belt, and lug (Figure 2D).

Enterococci (Figure 2E) were absent from the upper shaking rods and variable on all other surfaces. Counts were highest on the lower sidewall, catcher plates, and conveyor belt, similar to what was observed for total aerobes.

\subsection{Microbial Loads on Top-Loader Harvester Surfaces}

Two types of surfaces that are found only on top-loader harvesters, viz. the vertical conveyor belt (Figure 1H) and filling flap (Figure 1I), were sampled on three harvesters each in 2015 and 2016. Analysis of variance of the combined data from both years indicated no significant effects of surface or sampling time on the population densities of the five microorganism groups (Table 3). Microbial counts on these two surfaces (Table 3) were in a very similar range as those observed for the other surfaces discussed above (Figure 2).

\subsection{Microbial Loads on Fruit}

Analysis of variance indicated no effect of fruit sampling location (pre- or postharvester) and sampling time on the population densities of the five organism groups when the analysis was done separately by year (Table 4). However, when data from the 2 years were combined for analysis, both total aerobes and yeasts and molds were found to be significantly higher on post-harvester samples than on pre-harvester samples, although the effect for yeasts and molds was relatively small in magnitude (Figure 3A,B); none of the other comparisons were statistically significant (Table 4). Coliforms were consistently isolated from fruit at average densities of $10^{1}$ to $10^{2} \mathrm{CFU} / \mathrm{g}$ (Figure 3C), whereas fecal coliforms (Figure 3D) and enterococci (Figure 3E) were detected only rarely and at very low densities $<10^{1} \mathrm{CFU} / \mathrm{g}$. 
Table 3. Population densities $\left(\log _{10}(x+1)\right.$ colony-forming units per $\mathrm{cm}^{2} \pm$ standard error) of environmental and fecal indicator organisms on surfaces that are found only on top-loader blueberry harvesters (three each in 2015 and 2016) sampled at different times of the day.

\begin{tabular}{cccccc}
\hline & \multicolumn{5}{c}{ Organism Group } \\
\cline { 2 - 6 } $\begin{array}{c}\text { Surface and } \\
\text { Sampling } \\
\text { Time }\end{array}$ & $\begin{array}{c}\text { Total } \\
\text { Aerobes }\end{array}$ & $\begin{array}{c}\text { Yeasts and } \\
\text { Molds }\end{array}$ & Coliforms & $\begin{array}{c}\text { Fecal } \\
\text { Coliforms }\end{array}$ & Enterococci \\
\hline Vertical & & & & \\
conveyor & & & & \\
AM & $4.87 \pm 0.4$ & $5.02 \pm 0.3$ & $1.27 \pm 0.3$ & $0.12 \pm 0.1$ & $0.20 \pm 0.1$ \\
Noon & $7.63 \pm 1.1$ & $4.85 \pm 0.2$ & $0.90 \pm 0.2$ & $0.44 \pm 0.2$ & $0.77 \pm 0.1$ \\
PM & $5.12 \pm 1.0$ & $4.58 \pm 0.2$ & $0.53 \pm 0.2$ & $0.55 \pm 0.3$ & $0.52 \pm 0.1$ \\
Filling flap & & & & & \\
AM & $3.81 \pm 0.8$ & $4.33 \pm 0.4$ & $0.62 \pm 0.1$ & n.d. ${ }^{1}$ & n.d. \\
Noon & $5.15 \pm 0.8$ & $4.97 \pm 0.2$ & $0.96 \pm 0.2$ & $0.09 \pm 0.1$ & $0.09 \pm 0.1$ \\
PM & $4.96 \pm 1.5$ & $3.88 \pm 1.0$ & $1.00 \pm 0.3$ & n.d. & $0.32 \pm 0.3$ \\
ANOVA & & & & & \\
$p$-values & & & & 0.0727 & 0.1190 \\
Surface (S) & 0.2319 & 0.1846 & 0.8518 & 0.4506 & 0.2577 \\
Time (t) & 0.2693 & 0.2189 & 0.7292 & 0.5314 & 0.4718 \\
S $\times t$ & 0.4352 & 0.3753 & 0.0930 &
\end{tabular}

${ }^{1}$ Below detection limit.

Table 4. $p$-values of mixed-model analysis of variance for the effects of fruit sampling location (before entering or after leaving the harvester) and time (AM, noon, PM) on the population density $\left(\log _{10}(x+1)\right.$ colony-forming units per $g$ of fruit) of environmental and fecal indicator organisms across seven mechanical blueberry harvesters in each of 2015 and $2016^{1}$.

\begin{tabular}{|c|c|c|c|c|c|}
\hline \multirow[b]{2}{*}{ Factor } & \multicolumn{5}{|c|}{ Organism Group } \\
\hline & $\begin{array}{c}\text { Total } \\
\text { Aerobes }\end{array}$ & $\begin{array}{l}\text { Yeasts and } \\
\text { Molds }\end{array}$ & Coliforms & $\begin{array}{c}\text { Fecal } \\
\text { Coliforms }\end{array}$ & Enterococci \\
\hline \multicolumn{6}{|l|}{2015} \\
\hline Location (L) & 0.1667 & 0.2894 & 0.9710 & 0.3559 & 0.4645 \\
\hline Time (t) & 0.8896 & 0.3784 & 0.9319 & 0.3827 & 0.7671 \\
\hline $\mathrm{L} \times \mathrm{t}$ & 0.9352 & 0.8609 & 0.7368 & 0.3827 & 0.4983 \\
\hline \multicolumn{6}{|l|}{2016} \\
\hline Location (L) & 0.0849 & 0.1016 & 0.1038 & 1.0000 & 0.3559 \\
\hline Time (t) & 0.9867 & 0.9650 & 0.6154 & 0.6127 & 0.3827 \\
\hline \multicolumn{6}{|l|}{$\begin{array}{c}\text { Combined } \\
\text { years }\end{array}$} \\
\hline Location (L) & $\underline{0.0235}$ & $\underline{0.0446}$ & 0.1619 & 0.4000 & 0.2229 \\
\hline Time $(\mathrm{t})$ & $\overline{0.9041}$ & $\overline{0.5027}$ & 0.7685 & 0.7841 & 0.4358 \\
\hline $\mathrm{L} \times \mathrm{t}$ & 0.3119 & 0.9206 & 0.8910 & 0.1172 & 0.5990 \\
\hline
\end{tabular}

${ }^{1}$ Significant $p$-values are underlined.

\subsection{Identification of Mechanical Harvester Microorganisms}

Representative isolates obtained from mechanical harvester surfaces in this study included organisms from all three main groups: bacteria, yeasts, and molds (Table 5). Based on 16S rRNA analysis, common bacterial isolates were identified as various Bacillus species and Stenotrophomonas rhizophila. The Bacillus isolates included common environmental and soil-inhabiting species with a range of known attributes, including biocontrol, antibiotic production, and bioremediation. It should be noted, however, that exact species designation in the genus Bacillus requires the use of multi-locus sequence analysis or whole-genome sequencing [16]. Stenotrophomonas rhizophila is a well-known rhizobacterium with antifungal properties. Yeast species identified based on ITS sequencing and BLAST analysis were prevalent and included Rhodoturula mucilaginosa, Sporidiobolus pararoseus, Exobasidium maculosum, Cryptococcus laurentii, and Sporobolomyces koalae. Among these yeasts, R. mu- 
cilaginosa and C. laurentii can be opportunistic human pathogens, E. maculosum is a plant pathogen on blueberry [17], and S. pararoseus is a potential biocontrol agent. Molds were less prevalent and included Penicillium citrinum and Epicoccum nigrum, both of which are plant-associated and/or plant-pathogenic. From a food safety perspective, it is important to note that several of the representative bacterial, yeast, and mold isolates obtained in this study are known as opportunistic human pathogens (Table 5).
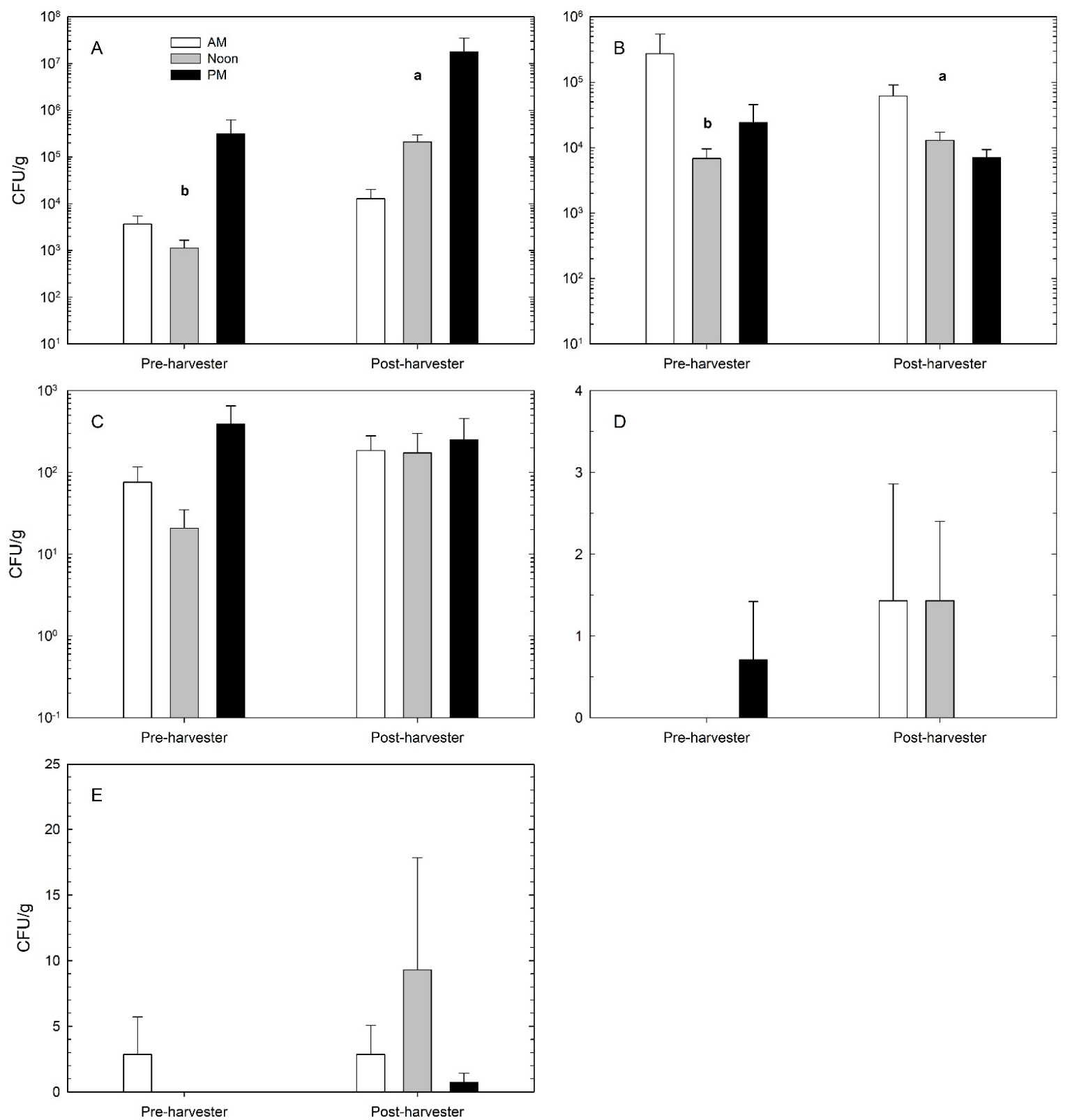

Figure 3. Microbial loads on fruit from blueberry mechanical harvesters in the field when sampled in the morning (AM), at noon, and in the evening (PM). Fruit were collected either just before the plant entered the tunnel of the harvester (pre-harvester) or from the berry lug immediately after the fruit had travelled through the harvester (post-harvester). (A) Total aerobes, (B) total yeasts and molds, (C) coliforms, (D) fecal coliforms, and (E) enterococci. Values are means and standard errors across seven harvesters sampled in each of 2 years. Bars with the same lower-case letters are not significantly different for comparison of the sample location main effect (Tukey's test, $p=0.05$ ). Analysis based on $\log _{10}(x+1)$-transformed values, untransformed values are shown in the figures. $\mathrm{CFU}=$ colony-forming units. 
Table 5. Presumptive identity of representative bacterial, yeast, and mold isolates obtained from blueberry mechanical harvester surfaces between 2015 and 2017.

\begin{tabular}{|c|c|c|c|c|}
\hline $\begin{array}{l}\text { Genbank } \\
\text { Accession }\end{array}$ & Tentative ID $^{1}$ & $\begin{array}{l}\text { Percent } \\
\text { Identity }\end{array}$ & $\begin{array}{c}\text { Query } \\
\text { Coverage }\end{array}$ & $\begin{array}{l}\text { Other Matches } \\
\text { (>98\% Identity) }\end{array}$ \\
\hline \multicolumn{5}{|l|}{ Bacteria } \\
\hline MT605426.1 & Bacillus sp. & $100 \%$ & $100 \%$ & $\begin{array}{c}\text { B. altitudinis, subtilis, } \\
\text { aerophilus, } \\
\text { stratophericus, aerius, } \\
\text { pumilus * }\end{array}$ \\
\hline KX588618.1 & $\begin{array}{l}\text { Stenotrophomonas } \\
\text { rhizophila }\end{array}$ & $100 \%$ & $100 \%$ & \multirow{5}{*}{$\begin{array}{c}\text { S. maltophilia * } \\
\text { B. siamensis, } \\
\text { amyloliquefaciens, } \\
\text { velezensis } \\
\text { B. aerius, altitudinis, } \\
\text { pumilus ***, } \\
\text { sporothermodurans } \\
\text { B. subtilis, } \\
\text { amyloliquefaciens, } \\
\text { methylotrophicus } \\
\text { B. tropicus, } \\
\text { thuringiensis, } \\
\text { paranthracis }\end{array}$} \\
\hline MN945445.1 & Bacillus subtilis & $100 \%$ & $99 \%$ & \\
\hline KC172020.1 & Bacillus aerophilus & $99.90 \%$ & $90 \%$ & \\
\hline MN865799.1 & Bacillus velezensis & $99.61 \%$ & $99 \%$ & \\
\hline MT642947.1 & Bacillus cereus* & $99.55 \%$ & $97 \%$ & \\
\hline GQ250095.1 & Bacillus pumilus ${ }^{* * *}$ & $99.46 \%$ & $91 \%$ & $\begin{array}{l}\text { B. altitudinis, } \\
\text { xiamenensis }\end{array}$ \\
\hline MT122832.1 & Bacillus aquimaris & $99.16 \%$ & $98 \%$ & \multirow{5}{*}{ B. vietnamensis } \\
\hline MK968313.1 & $\begin{array}{l}\text { Microbacterium } \\
\text { paraoxydans }\end{array}$ & $97.66 \%$ & $99 \%$ & \\
\hline Yeasts & & & & \\
\hline MG471022.1 & Sporobolomyces koalae & $100 \%$ & $94 \%$ & \\
\hline КР346984.1 & $\begin{array}{l}\text { Sporidiobolus } \\
\text { pararoseus }\end{array}$ & $99.65 \%$ & $95 \%$ & \\
\hline JQ425370.1 & Rhodotorula glutinis & $99.50 \%$ & $96 \%$ & \multirow[t]{3}{*}{$\begin{array}{c}\text { Rhodotorula } \\
\text { mucilaginosa * }\end{array}$} \\
\hline KR262386.1 & $\begin{array}{l}\text { Exobasidium } \\
\text { maculosum ** }\end{array}$ & $99.46 \%$ & $92 \%$ & \\
\hline KР346983.1 & $\begin{array}{l}\text { Sporidiobolus } \\
\text { pararoseus }\end{array}$ & $99.32 \%$ & $95 \%$ & \\
\hline KT899784.1 & Cryptococcus laurentii * & $99.25 \%$ & $96 \%$ & \multirow[t]{2}{*}{ Papiliotrema laurentii } \\
\hline KX067832.1 & $\begin{array}{l}\text { Sporidiobolus } \\
\text { pararoseus }\end{array}$ & $99.15 \%$ & $100 \%$ & \\
\hline \multicolumn{5}{|l|}{$\begin{array}{l}\text { Filamentous } \\
\text { fungi }\end{array}$} \\
\hline MN398977.1 & Penicillium citrinum & $100 \%$ & $99 \%$ & \multirow[t]{2}{*}{$\begin{array}{l}\text { Penicillium } \\
\text { brevicompactum }\end{array}$} \\
\hline KX664336.1 & Epicoccum nigrum ${ }^{*, * *}$ & $100 \%$ & $97 \%$ & \\
\hline EU489900.1 & $\begin{array}{l}\text { Uncultured } \\
\text { Ascomycota }\end{array}$ & $99.81 \%$ & $99 \%$ & $\begin{array}{c}\text { Dothidomycete, } \\
\text { Phoma herbarum, } \\
\text { Leptosphaeria sacchari }\end{array}$ \\
\hline
\end{tabular}

${ }^{1}$ Isolates were sequenced at the 16S rRNA (primers 27F and 1492R [14]) and ITS (primers ITS1F and ITS4 [15]) regions for bacteria and yeasts/molds, respectively. Preliminary identifications based on BLAST comparisons with sequences available in NCBI Genbank. In all cases, E-value $=0.0 .{ }^{*}$ and ${ }^{* *}$ denotes opportunistic human pathogens and plant pathogens, respectively, based on literature information.

\section{Discussion}

Each step from production and harvest to post-harvest handling and packaging can contribute to a change in the microbial load of fresh produce [18]. Microbial hygiene studies have been conducted in blueberry at the packing plant level on packing line surfaces but not at the farm level on harvesting equipment. In a recent microbial survey in blueberry packing plants in the same blueberry production region of southern Georgia [3], 
population densities of total aerobes, yeasts and molds, and coliforms were found to be at least two orders of magnitude lower on various packing line surfaces compared with the harvester surfaces reported here. These differences between packing line and harvester surfaces are not surprising and relate to the respective environments with packing facilities being indoors under climate control and produce buyers requiring strict daily cleaning and sanitization practices [19], compared with the outdoor and weather-impacted harvester environment that naturally exposes surfaces to a wide array of microorganisms. Furthermore, although growers understand the importance of microbial hygiene in the field, cleaning and sanitization practices are more difficult to implement on field equipment. For example, growers often have to wait until the end of the day to clean and sanitize harvesters but sometimes they can clean them during the lunch break if potable water is available at the particular site they are harvesting. Growers also have the added constraint of needing to transport harvesters to multiple farms and field sites during the day, while also maintaining a timely picking schedule to avoid fruit quality issues. Thus, opportunities for cleaning and sanitization may not come conveniently and practically given time and weather constraints. Finally, growers need more information about the relative efficacy of sanitizers available on the market, their corrosive impact on equipment, and their safety properties with regard to the applicator and during storage [13].

The present study showed, for the first time, that food contact surfaces on blueberry mechanical harvesters differ in the loads of environmental and fecal contamination indicator organisms they harbor. Specifically, microbial loads were typically lowest on surfaces at the front of the harvester (shaking rods and upper sidewall) and highest on horizontal surfaces and/or those located at the bottom of the harvester (lower sidewall, catcher plates, and conveyor belt). Because of their location and orientation, the latter surfaces accumulate more dirt and plant residue such as leaves or juice from damaged berries, which may facilitate microbial attachment, growth, and survival. Furthermore, it is well established that conveyor belts can be problematic sources of microorganisms in the food industry. One study in a cabbage packing facility found Listeria spp. to survive and proliferate readily on conveyor belts in particular [20]. In blueberry packing plants, packing lines under regular cleaning and sanitization protocols consistently harbored microbes on conveyor belts, including total aerobes $\left(10^{2}\right.$ to $\left.10^{3} \mathrm{CFU} / \mathrm{cm}^{2}\right)$, yeasts and molds $\left(\sim 10^{2} \mathrm{CFU} / \mathrm{cm}^{2}\right)$, and coliforms $\left(\sim 10 \mathrm{CFU} / \mathrm{cm}^{2}\right)$ [3].

Microbes were recovered consistently-albeit at variable densities-from berry lugs, which are used to transport fruit from the harvester in the field to the packing plant. This is consistent with the results of a previous microbial hygiene study in blueberry packing plants [3], in which the lug surface similarly was found to harbor environmental microbes, in particular total aerobes and yeasts and molds. Lugs are regularly cleaned and sanitized. Typically, a lug washer is utilized in which detergent and water are used to clean the lugs and sanitizer is sprayed onto the lug surface during the second step; however, during the peak of harvest season, demand for lugs is high, and received lugs may still be wet from the cleaning and sanitization process. This residual moisture may facilitate microbial recolonization. In addition, lugs are frequently touched by hand as they are moved back and forth between the field and the packing plant, providing additional opportunities for microbial contamination. Finally, storage conditions may be important as well; for example, if stored temporarily under equipment shelters, birds may roost above the stacked lugs and contribute to microbial contamination. With increased awareness of the lug as a potential carrier of microbes, improved cleaning, sanitization, and storage protocols for lugs should be implemented at the farm and packing plant levels.

Few microbiological criteria for the assessment of hygiene conditions of food contact surfaces are available in the U.S., and the guidance that does exist applies solely to cleaned and sanitized food contact surfaces in indoor packing/processing facilities or food service establishments [3]. For example, if the microbial scale considered by Fung and Goetsch [21] is applied to the microbial loads recovered from harvester surfaces in the present study, 
most surfaces would be considered to harbor "intermediate" $\left(10^{3}\right.$ to $\left.10^{4} \mathrm{CFU} / \mathrm{cm}^{2}\right)$ or "high" $\left(10^{5}\right.$ to $\left.10^{6} \mathrm{CFU} / \mathrm{cm}^{2}\right)$ microbial levels.

The overall average microbial loads on fruit in this study were $2.71,3.59,0.80 \mathrm{log}$ $\mathrm{CFU} / \mathrm{g}$ for total aerobes, total yeasts/molds, and coliforms, respectively. These levels are slightly lower than those reported on fruit sampled in blueberry packing plants by Quansah et al. [12], 3.90, 4.13, and $1.19 \mathrm{log}$ CFU/g for the same organism groups determined by fruit rinsing. The microbial levels on fruit observed in our study are also lower than the acceptance thresholds used typically by buyers of processed blueberry fruit, i.e., $5.00 \mathrm{log}$ $\mathrm{CFU} / \mathrm{g}$ for aerobes and $4.88 \mathrm{log} \mathrm{CFU} / \mathrm{g}$ for yeasts and molds (U.S. Highbush Blueberry Council, Folsom, CA, USA, unpublished). When data from the two years were analyzed separately in the present study, the passage of fruit in the field through the harvester did not affect microbial loads on the fruit significantly. However, when data were combined, significantly higher counts of the two environmental microorganism groups (total bacteria and total yeasts/molds) were found on fruit exiting the harvester, most likely due to the increased statistical power associated with analyzing the combined data set. In this context, it is important to note that high microbial counts on produce do not necessarily correlate with decreased fruit quality and shelf life [22].

Regardless of the method of analysis (separately by year or combined), there was no significant effect of the mechanical harvesting process on the plate counts of coliforms, fecal coliforms, and enterococci recovered from harvested fruit. In particular, fecal coliforms and enterococci were recovered only sporadically and at very low population densities. This result is consistent with a previous study showing that regardless of harvesting method (hand vs. machine), loads of fecal indicator organisms such as coliforms and E. coli on blueberry fruit were absent or very low [11].

When representative microbial isolates obtained from harvester surfaces were subjected to presumptive identification using $16 \mathrm{~S}$ rRNA or ITS sequencing, common plantand soil-associated organisms such as various Bacillus spp., the pigmented yeasts Sporidiobolus and Rhodotorula, and the molds Penicillium spp. and Epicoccum nigrum were found to dominate. Many of these organisms are considered ubiquitous in the environment and pose limited risks to plant or human health. However, Bacillus pumilus, E. nigrum, and the yeast Exobasidium maculosum are known plant pathogens [17,23,24], the latter on blueberry. Furthermore, Bacillus cereus can be a cause of gastrointestinal disease in humans [25], and several of the other species isolated from harvester surfaces, including B. pumilus [26], Rhodotorula mucilaginosa [27], Cryptococcus laurentii [28], and E. nigrum [29] are capable of causing opportunistic infections in immunocompromised patients. As such, more stringent cleaning and sanitization practices are recommended for blueberry harvesters to minimize any risks posed by these ubiquitous environmental microbes.

Neither harvester technology nor the cleaning and sanitization practices applied to these harvesters have changed substantially in the Georgia blueberry industry since this study was conducted $\sim 5$ years ago. As such, the results serve as an important baseline for documenting future improvements in cleaning protocols that help improve the hygienic conditions of blueberry harvesters and the microbial quality of machine-harvested fruit.

\section{Conclusions}

This study showed that food contact surfaces on mechanical harvesters used in commercial blueberry production harbored high levels of total aerobes and total yeasts and molds (including some common species tentatively identified as opportunistic pathogens), especially on horizontal surfaces and/or those located at the bottom of the harvester such as the lower sidewall of the tunnel, the catcher plates, and the conveyor belt. These surfaces therefore should be targeted in particular by cleaning and sanitization practices. There was also evidence that passage through the harvester increased the levels of these environmental microorganisms on fruit in the field. In contrast, fecal indicator organisms of potential human health concern such as fecal coliforms and enterococci were detected only sporadically and at very low densities on harvester surfaces and blueberry fruit, and there 
was no evidence that passage through the harvester increased levels of these organisms on the fruit in the field. Berry lugs consistently harbored microbial loads, and given their movement back and forth between the field and the packing plant, deserve particular attention in terms of cleaning, sanitization, and storage protocols.

Author Contributions: R.M.H.-Methodology, Formal Analysis, Investigation, Data Curation, Writing (Original Draft); J.C.-Methodology, Resources, Writing (Review \& Editing), Supervision, Funding Acquisition; H.G.-Methodology, Investigation; H.S.-Conceptualization, Methodology, Investigation, Resources, Writing (Review \& Editing), Supervision, Project Administration, Funding Acquisition. All authors have read and agreed to the published version of the manuscript.

Funding: This work was supported by the National Institute of Food and Agriculture, U.S. Department of Agriculture, under award number USDA-NIFA-SCRI-004530.

Institutional Review Board Statement: Not applicable.

Informed Consent Statement: Not applicable.

Data Availability Statement: The raw data underlying these analyses are available from the corresponding author upon reasonable request.

Acknowledgments: We thank the blueberry growers who allowed us to survey their mechanical harvesters during the 2015 and 2016 harvest seasons. Skilled technical assistance by Danielle Ludwig and Frannie Martin is gratefully acknowledged.

Conflicts of Interest: The authors declare no conflict of interest.

\section{References}

1. Grover, A.K.; Chopra, S.; Mosher, G.A. Food safety modernization act: A quality management approach to identify and prioritize factors affecting adoption of preventive controls among small food facilities. Food Control 2016, 66, 241-249. [CrossRef]

2. Taylor, M.R. Will the food safety modernization act help prevent outbreaks of foodborne illness? N. Engl. J. Med. 2011, 365, e18. [CrossRef]

3. Gazula, H.; Quansah, J.; Allen, R.; Scherm, H.; Li, C.; Takeda, F.; Chen, J. Microbial loads on selected fresh blueberry packing lines. Food Control 2019, 100, 315-320. [CrossRef]

4. Brackett, R.E. Incidence, contributing factors, and control of bacterial pathogens in produce. Postharvest Biol. Tech. 1999, 15, 305-311. [CrossRef]

5. Hwang, S.-F.; Howard, R.J.; Strelkov, S.E.; Gossen, B.D.; Peng, G. Management of clubroot (Plasmodiophora brassicae) on canola (Brassica napus) in western Canada. Can. J. Plant Pathol. 2014, 36, 1-4. [CrossRef]

6. Poumian, A.M. Disinfection of trucks and trailers. Rev. Sci. Tech. Off. Int. Epiz. 1995, 14, 171-176.

7. Cárdenas, C.; Molina, K.; Heredia, N.; García, S. Evaluation of microbial contamination of tomatoes and peppers at retail markets in Monterrey, Mexico. J. Food Prot. 2013, 76, 1475-1479. [CrossRef]

8. International Commission on Microbiological Specifications for Foods. Sampling to assess control of the environment. In Microorganisms in Foods 7: Microbiological Testing in Food Safety Management; Buchanan, R., Ed.; Springer: Cham, Switzerland, 2018; pp. 263-292. [CrossRef]

9. Savichtcheva, O.; Okabe, S. Alternative indicators of fecal pollution: Relations with pathogens and conventional indicators, current methodologies for direct pathogen monitoring and future application perspectives. Water Res. 2006, 40, $2463-2476$. [CrossRef]

10. Sales, M. An Evaluation of Blackberry Harvest Sanitation and the Ability of Foodborne Pathogens to Survive in Blackberry Products. Master's Thesis, Department of Food Science and Technology, Oregon State University, Corvallis, OR, USA, 2013.

11. Mehra, L.K.; MacLean, D.D.; Savelle, A.T.; Scherm, H. Postharvest disease development on southern highbush blueberry fruit in relation to berry flesh type and harvest method. Plant Dis. 2013, 97, 213-221. [CrossRef] [PubMed]

12. Quansah, J.K.; Gazula, H.; Holland, R.; Scherm, H.; Li, C.; Takeda, F.; Chen, J. Microbial quality of blueberries for the fresh market. Food Control 2019, 100, 92-96. [CrossRef]

13. Holland, R.M. Fruit Microbial Hygiene Associated with Mechanical Harvesting and Injuries, and Stem Blight in Relation to Mechanical Hedging and Crown Bark Inclusions in Blueberry. Ph.D. Thesis, Department of Plant Pathology, University of Georgia, Athens, GA, USA, 2021.

14. Frank, J.A.; Reich, C.I.; Sharma, S.; Weisbaum, J.S.; Wilson, B.A.; Olsen, G.J. Critical evaluation of two primers commonly used for amplification of bacterial 16S rRNA genes. Appl. Environ. Microbiol. 2008, 74, 2461-2470. [CrossRef] [PubMed]

15. Op De Beeck, M.; Lievens, B.; Busschaert, P.; Declerck, S.; Vangronsveld, J.; Colpaert, J.V. Comparison and validation of some ITS primer pairs useful for fungal metabarcoding studies. PLoS ONE 2014, 9, e97629. [CrossRef] 
16. Fan, B.; Blom, J.; Klenk, H.-P.; Borriss, R. Bacillus amyloliquefaciens, Bacillus velezensis, and Bacillus siamensis form an "operational group B. amyloliquefaciens" within the B. subtilis species complex. Front. Microbiol. 2017, 8, 22. [CrossRef]

17. Ingram, R.J.; Ludwig, H.D.; Scherm, H. Epidemiology of Exobasidium leaf and fruit spot of rabbiteye blueberry: Pathogen overwintering, primary infection and disease progression on leaves and fruit. Plant Dis. 2019, 103, 1293-1301. [CrossRef]

18. Johnston, L.M.; Jaykus, L.-A.; Moll, D.; Martinez, M.C.; Ancisco, J.; Mora, B.; Moe, C.L. A field study of the microbiological quality of fresh produce. J. Food Prot. 2005, 68, 1840-1847. [CrossRef] [PubMed]

19. Howard, L.R.; Gonzalez, A.R. Food safety and produce operations: What is the future? HortScience 2001, 36, 33-39. [CrossRef]

20. Prazak, A.M.; Murano, E.A.; Mercado, I.; Acuff, G.R. Prevalence of Listeria monocytogenes during production and postharvest processing of cabbage. J. Food Prot. 2002, 65, 1728-1734. [CrossRef] [PubMed]

21. Fung, D.Y.C.; Goetsch, S.J. Introduction of Food Microbiology. Department of Animal Sciences and Industry; Kansas State University: Manhattan, KS, USA, 1991.

22. Nguyen-the, C.; Carlin, F. Fresh and processed vegetables. In The Microbiological Safety and Quality of Food; Lund, B.M., Baird-Parker, A.C., Gould, G.W., Eds.; Aspen Publishers: Gaithersburg, MD, USA, 2000; pp. 620-684.

23. Kovaleva, V.A.; Shalovylo, Y.I.; Gorovik, Y.N.; Lagonenko, A.L.; Evtushenkov, A.N.; Gout, R.T. Bacillus pumilus-A new phytopathogen of Scots pine. J. For. Sci. 2015, 61, 131-137.

24. Taguiam, J.D.; Evallo, E.; Balendres, M.A. Epicoccum species: Ubiquitous plant pathogens and effective biological control agents. Eur. J. Plant Pathol. 2021, 159, 713-725. [CrossRef]

25. Bottone, E.J. Bacillus cereus, a volatile human pathogen. Clin. Microbiol. Rev. 2010, 23, 382-398. [CrossRef]

26. Bentur, H.N.; Dalzell, A.M.; Riordan, F.A.I. Central venous catheter infection with Bacillus pumilus in an immunocompetent child: A case report. Ann. Clin. Microbiol. Antimicrob. 2007, 6, 12. [CrossRef]

27. Deligios, M.; Fraumene, C.; Abbondio, M.; Mannazzu, I.; Tanca, A.; Addis, M.F.; Uzzau, S. Draft genome sequence of Rhodotorula mucilaginosa, an emergent opportunistic pathogen. Genome Announc. 2015, 3, e00201-15. [CrossRef] [PubMed]

28. Kordossis, T.; Avlami, A.; Velegraki, A.; Stefanou, I.; Georgakopoulos, G.; Papalambrou, C.; Legakis, N.J. First report of Cryptococcus laurentii meningitis and a fatal case of Cryptococcus albidus cryptococcaemia in AIDS patients. Med. Mycol. 1998, 36, 335-339. [CrossRef] [PubMed]

29. Suraiya, S.; Azira, N. PP-067 Intramuscular Epicoccum nigrum infection in an immunocompromised patient: A case report. Int. J. Infect. Dis. 2010, 14, S45-S46. [CrossRef] 